\title{
Facets of the psychotherapy relationship: a metaphorical approach
}

\author{
Tomáš Řiháček, Jan Roubal, Katarína Motalová \\ Department of Psychology, Faculty of Social Studies, Masaryk University, Brno, Czech Republic
}

\begin{abstract}
Although many separate aspects of the psychotherapy relationship have been studied, including empathy, working alliance, and self-disclosure, a metaphorical approach has the potential to generate a more holistic perspective of this phenomenon. Hence, the goal of this study was to explore the nature of the psychotherapy relationship from the psychotherapists' perspective using a metaphorical approach. In an online survey, a sample of $\mathrm{N}=373$ Czech psychotherapists and counselors rated a set of relational metaphors in terms of how accurately they depicted their roles in their relationships with their clients. The single most endorsed metaphor for the practitioner's role was a guide. Furthermore, the principal component analysis identified three relational components, namely, Mentor, Resource Supplier, and Remedy Distributor. The associations among these components and multiple practitioners' variables, including demographic and practice-related variables and theoretical orientation, were explored. These three components represent general dimensions of the psychotherapy relationship that cut across various theoretical orientations and, thus, define psychotherapy relationships in a general sense.
\end{abstract}

Key words: Metaphor; professional role; psychotherapy relationship; survey; theoretical orientation.

Correspondence: Tomáš Řiháček, Department of Psychology, Faculty of Social Studies, Masaryk University, Joštova 10, 60200 Brno, Czech Republic.

E-mail: rihacek@fss.muni.cz

Citation: Řiháček, T., Roubal, J., \& Motalová, K. (2020). Facets of the psychotherapy relationship: a metaphorical approach. Research in Psychotherapy: Psychopathology, Process and Outcome, 23(3), 311-319. doi: 10.4081/ripppo.2020.468

Funding: this study was supported by the Czech Science Foundation under Grant GA18-08512S.

Contributions: Tř, designed the study, collected the data, conducted the analysis, and wrote the manuscript. JR and KM, both participated in data analysis and wrote the manuscript.

Conflict of interests: the authors declare no potential conflict of interests.

Ethical approval and consent to participate: the project was approved by the Research Ethics Committee of the Masaryk University (ref. no. EKV-2016-006).

Availability of data and material: the data are available upon request from the first author.

Received for publication: 23 June 2020.

Revision received: 2 September 2020.

Accepted for publication: 12 September 2020.

This work is licensed under a Creative Commons Attribution NonCommercial 4.0 License (CC BY-NC 4.0).

${ }^{\circ}$ Copyright: the Author(s), 2020

Licensee PAGEPress, Italy

Research in Psychotherapy:

Psychopathology, Process and Outcome 2020; 23:311-319

doi:10.4081/ripppo.2020.468

\section{Introduction}

The psychotherapy relationship is considered a fundamental condition for and a means of psychotherapy change (Norcross, 2011). It is present in all psychotherapy systems, and it is probably the most often cited common factor in psychotherapy and counseling (Grencavage \& Norcross, 1990). The psychotherapy relationship is a complex phenomenon that can be broadly defined as "the feelings and attitudes that counseling participants have toward one another, and the manner in which these are expressed" (Gelso $\&$ Carter, 1985, p. 159). Many partial aspects of the relationship have been recognized and studied empirically. In their tripartite model, Gelso and Carter distinguished three constituent parts of the psychotherapy relationship: working alliance, transference-countertransference configuration, and the real relationship. Of these three, the working alliance has been most extensively subjected to empirical research and has been found to be a robust predictor of outcome (Horvath, Del Re, Flückiger, \& Symonds, 2011). Other aspects of the psychotherapy relationship that received empirical support include empathy, congruence, and unconditional positive regard (Crits-Christoph, Gibbons, \& Mukherjee, 2013), group cohesion (Burlingame, McClendon, \& Alonso, 2011), therapist self-disclosure (ZivBeiman, 2013), countertransference (Gelso \& Hayes, 2007), and the reparation of alliance ruptures (Safran, Muran, \& Eubanks-Carter, 2011).

Psychotherapists may differ in the relational manner with which they deliver the treatment (Fernández-Álvarez, García, Lo Bianco, \& Corbella Santomá, 2003; Řiháček \& Roubal, 2017a). Furthermore, the degree of match between 
a therapist's relational style and a client's relational preferences may be an important factor influencing treatment outcomes (Cooper, Norcross, Raymond-Barker, \& Hogan, 2019). Therefore, it is essential to understand the variety of relational styles used by therapists in practice. Although the abovementioned concepts allow us to evaluate the quality of the therapeutic relationship and its connection to the outcome, they do not convey much information about how the relationship is represented in the therapists' or clients' immediate experience. To gain new insights into this problem, we applied a metaphorical approach.

\section{Metaphorical approach}

Well-defined concepts are crucial to understand reality and communicate this understanding to others. However, when concepts become used in a too rigid and definitive manner, they may eventually prevent further evolution of a field (Kuhn, 1996). Metaphors are fuzzy and experiential in nature. Unlike analytic definitions, they are rich in connotative meaning, convey implicit and emotional content, and are sensitive to culture-based experience (Lakoff \& Johnson, 2003). Metaphors can make accessible meanings that are otherwise difficult to verbalize. Therefore, they may be particularly suitable to capture complex relational meanings beyond established concepts.

Metaphors are ubiquitous in our everyday lives. As Lakoff and Johnson (2003) put it: "Our ordinary conceptual system, in terms of which we both think and act, is fundamentally metaphorical in nature" (p. 4). They have been used in psychology from its very beginning and have often functioned as predecessors of formal models (Leary, 1990). The vital role of metaphors in all major psychotherapy schools has been advocated by Kopp (1995) and they have been plentifully used in psychotherapy research as well (e.g., alliance ruptures). Metaphors may thus help us consolidate a common-sense view of psychotherapy.

\section{Relational metaphors in psychotherapy and medicine}

The use of metaphors has been studied in the context of the psychotherapy process (Angus \& Rennie, 1988, 1989; Rowat, Stefano, \& Drapeau, 2008) and supervision (Young \& Borders, 1999). Austin, Bergum, Nuttgens, \& Peternelj-Taylor (2006) argued for metaphors as a suitable means for reflection of professional helping relationships. However, we are not aware of any study that has used a metaphorical approach to explore the nature of the psychotherapy relationship systematically. We have found only anecdotal attempts, such as that of Corsini (2008), who compared psychotherapists to detectives and counselors to teachers.

Since the therapeutic relationship shares some aspects with the doctor-patient relationship, relational metaphors developed in the field of medicine may possess some relevance for psychotherapy as well. Beisecker and Beisecker (1993) reflected on two leading metaphors of the physician-patient relationship, namely, paternalism and consumerism. Whereas paternalism denotes a relationship based on the physicians' obligations, beneficence, trust, and principles of good medical care, consumerism stresses the patients' rights, accountability, individual preferences, and values (Beisecker \& Beisecker, 1993). Less formally, Carter (1989) explored other metaphors, such as parent, fighter, technician, teacher, friend, stranger, coach, repair person, or fellow detective, all of which have been used to describe various aspects or forms of the physician-patient relationship.

\section{Aims of the study}

Accordingly, this study aimed to explore the nature of the psychotherapy relationship from the perspective of the psychotherapist using a metaphorical approach. To address this aim, data from a national survey on Czech psychotherapists and counselors were used and subjected to the principal component analysis. Since this was an exploratory study, no a priori hypotheses were formulated about the components. However, we expected that the components would be related to the therapists' gender, practice-related variables, and theoretical orientation.

\section{Materials and Methods}

\section{Participants}

A sample of $\mathrm{N}=373$ Czech psychotherapists and counselors, $64 \%$ of whom were female, participated in the study. Their age varied between 25 and 71 years ( $M=40.17, S D=10.17)$, and their length of practice ranged from 0.5 to 45 years, with $62 \%$ of the participants having ten or fewer years of practice. While $51.7 \%$ had fully completed their training at the time of data collection, the remaining participants were in various stages of training completion. Regarding theoretical orientations, the most endorsed, as measured on a scale of 0 to 5 , was the humanistic/experiential orientation $(M=3.08, S D=1.51)$, followed by the systemic/postmodern orientation $(M=2.94$, $S D=1.65)$, the psychodynamic/psychoanalytic orientation $(M=2.66, S D=1.61)$, and the cognitive/behavioural orientation $(M=1.96, S D=1.19)$.

The participants represented various primary professions: psychology $(62.5 \%)$, social work $(19.0 \%)$, pedagogy $(17.4 \%)$, psychiatry $(5.9 \%)$, non-medical health professions $(3.2 \%)$, addictology (2.4\%), medicine other than psychiatry $(1.9 \%)$, and others. As some participants stated more than one primary profession, the sum exceeds $100 \%$. The participants practiced psychotherapy in various settings, including private practice $(49.6 \%)$, social services $(34.3 \%)$, health services $(33.8 \%)$, educational 
settings (16.1\%), and armed and rescue services (8.6\%). Again, as some participants practiced in multiple settings, the sum exceeds $100 \%$.

\section{Instruments}

A questionnaire was developed for this study. The first part contained demographic items, i.e., age, gender, and primary profession. The second part was composed of a list of relational metaphors that was developed to capture a range of aspects of the psychotherapy relationship. The list was developed in three steps. First, the authors (two professors with $15+$ years of psychotherapeutic practice and a doctoral student) each brainstormed a list of metaphors for the therapists' role which were intended to cover a broad range of possible meanings. Second, they merged the lists and removed metaphors that they deemed irrelevant and merged those that were similar in meaning. The reduction was motivated by the fact that the metaphor section was a part of a longer questionnaire and, therefore, had to be kept brief. Third, the authors critically inspected the list to see whether any essential aspect was missing. Furthermore, a draft version of the questionnaire was presented to 20 psychotherapists to gather their comments and suggestions. This process resulted in a list of 12 relational metaphors. The list was presented to the respondents with the following instruction: "Imagine that your relationship to your client could be expressed by a metaphor. Please, tell us to what extent does each of the following metaphors capture how you approach your clients. Take into account the last year of your psychotherapeutic/counseling practice." Each metaphor was then rated on a six-point Likert-type scale, as follows: $0=$ never, $1=$ rarely, $2=$ sometimes, $3=$ often, $4=$ in most sessions, $5=$ in every session.

The third part of the questionnaire focused on trainingand practice-related items and included length of time practicing (in years); field of practice, such as health care, social services, educational setting, armed and rescue services, private practice, or other; highest level of client problem severity in one's practice; workload, which was measured as an average number of sessions per week; theoretical orientation; frequency of supervision; and level of training completion. All practice-related questions were framed by an introductory statement that asked participants to answer the question based on the last year of their practice.

Client problem severity was measured by an item adopted from the Development of Psychotherapists Common Core Questionnaire (DPCCQ, Orlinsky \& Rønnestad, 2005) and was composed of eight severity levels from "absent or minimal symptoms; socially effective; generally satisfied with life; no more than everyday problems or concerns" to "real danger of hurting self or others [e.g., suicide attempts, recurrent violence] or failure to maintain minimal personal hygiene, or gross impairment in communication [e.g., largely incoherent or mute]." Participants were asked to choose the highest severity level they commonly encountered in their practice. This score was used to represent the level of impairment of the participant's clientele.

Broad-band theoretical orientation was measured using four items to investigate an endorsement of each of the four broadly defined theoretical orientations: cognitive/behavioral, humanistic/experiential, psychodynamic/psychoanalytic, and systemic/postmodern. The level of endorsement was measured on a six-point scale, as follows: $0=$ not at all, $1=$ slightly, $2=$ somewhat, $3=$ moderately, $4=$ greatly, $5=$ very greatly (adopted from the DPCCQ, Orlinsky \& Rønnestad, 2005).

The questionnaire was part of a wide national survey and contained several other items that were not analyzed as part of this study. Partial results based on the same dataset were previously reported in Řiháček and Roubal (2017b, 2019, 2020).

\section{Procedure}

The project was approved by the Research Ethics Committee of the by Masaryk University (ref. no. EKV2016-006). A web-based version of the questionnaire was developed using the LimeSurvey platform (LimeSurvey Project Team, 2015). To maximize the sample size, several recruitment methods were used. First, umbrella associations for Czech psychotherapy and counseling practitioners were asked to distribute the questionnaire to their membership. Second, all Czech psychotherapy training institutes were asked to distribute the questionnaire to their graduates and their trainees. Third, personal e-mails and Facebook were used to increase participation.

Statistical analysis was conducted using $\mathrm{R}$ version 3.4.0 ( $\mathrm{R}$ Core Team, 2017). To find a more parsimonious description of the set of relational metaphors, principal component analysis (PCA) was conducted (Henson \& Roberts, 2006) on the metaphor items. Oblique rotation (direct oblimin) was chosen to rotate the components, as it was reasonable to expect correlated components. The number of components to extract was determined by the means of Horn's parallel analysis (Horn, 1965) using the 95th percentile criterion (O'Connor, 2000), Kaiser's criterion (eigenvalue $>1$ ) and a scree plot, as well as by the interpretability of the model. Finally, component scores were derived for each participant based on the structure matrix. PCA was conducted using the psych package (Revelle, 2016), and parallel analysis was conducted using the hornpa package (Huang, 2015).

To predict the use of the components identified in the previous step, a multiple regression analysis was conducted for each component. Two regression models were fitted. In Model 1, gender and four practice-related variables, namely, length of practice, highest level of severity, workload, and frequency of supervision, were used to predict component scores. In Model 2, four variables measuring practitioners' endorsement of the four broadband theoretical orientations were added to the predic- 
tors used in Model 1. Predictors were entered into the model using the forced entry method and no centering was applied.

The homoscedasticity and linearity assumptions were checked visually, the absence of multicollinearity was assessed using the variance inflation factor, independence of errors was tested using the Durbin-Watson test, the distribution of residuals was tested using the Shapiro-Wilk test, and visual confirmation was conducted. The regression analysis was conducted using the car (Fox \& Weisberg, 2011) and lmSupport (Curtin, 2017) packages.

\section{Results}

\section{Descriptive analysis}

We obtained 794 responses, 416 of which were incomplete and thus excluded ${ }^{1}$. Five respondents stated they had no psychotherapy training experience at all and, therefore, were excluded from the study. This yielded a final sample of $N=373$.

Descriptive statistics of the metaphor variables are reported in Table 1. The single most endorsed metaphor was guide, with a median value of 4 (in most sessions). It was followed by confessor, with a median value of 3 (often), and detective and consultant, with median values of 2 (sometimes). All other metaphors were perceived as rarely characterizing the respondents' work with clients. The least fitting metaphor was educator, where most of the respondents reported they never adopted this role.

\section{Principal component analysis}

The Kaiser-Meyer-Olkin measure verified the sampling adequacy for the analysis, $K M O=.74$, and the $K M O$ values for individual items ranged from .55 to .85 . Bartlett's test of sphericity, $\chi^{2}(66)=970.97, \mathrm{P}<0.001$, indicated that correlations between items were sufficiently large for the PCA. While a parallel analysis indicated that three components should be extracted, Kaiser's criterion and the scree plot converged on a four-component solution. We explored both solutions and found the three-component model to be superior in terms of interpretability and cleaner structure.

Table 2 presents the rotated component solution. The first component was defined by four metaphors, all of which share a mentor-type attitude, i.e., coach, teacher, educator, and adviser, and thus, this component was termed Mentor. The second component consisted of a set

Out of the 416 incomplete responses, 134 (32\%) respondents read only the introductory page of the questionnaire and did not continue to the survey, 115 (28\%) opened the survey but did not answer any question, and $78(19 \%)$ finished completing the questionnaire after the first page containing demographic information, but before they were presented with the list of metaphors. Therefore, we assume that the reason for non-participation was largely an overall unwillingness to participate in the survey, rather than any specific reluctance to respond to the metaphors. of five metaphors that embodied the aspect of an intimate, emotionally laden relationship in which the therapist personally invests himself/herself, i.e., confessor, friend, and model, or acted as a provider of information or opinion, i.e., detective and consultant. In either case, the therapist became a resource for the client to use either informationally or emotionally, and therefore, we named this component Resource Supplier. The third component was defined by two metaphors expressing an emphasis on pathology and expert attitude, i.e., doctor and repairer, and by the metaphor of educator, which tends to share the concept of expert attitude with the first two. Furthermore, it was negatively defined by the metaphor of guide, which tends to have, at least in the context of psychotherapy, the opposite connotations, i.e., non-expertise and a non-pathologizing attitude. Consequently, this dimension was termed Remedy Distributor. Together, these components explained $52.8 \%$ of the variance, and the component intercorrelations were practically negligible $\left(r_{12}=0.19, r_{13}=0.12\right.$, and $\left.r_{23}=0.07\right)$.

\section{Prediction of component scores}

Two multiple regression analyses (Model 1 and Model 2) were run for each component, and the results are presented in Table 3. All predictors were dichotomized using the median as the split point because they were either ordinal or non-normally distributed. Three observations were excluded due to missing data for one or more predictors. No multivariate outliers were removed. However, as the distribution of the predicted variable (i.e., component scores) was positively skewed in two cases, it was transformed using exponential transformation to produce normally distributed residuals. Furthermore, three univariate outliers were removed in the case of the third component for the same reason.

Model 1 was nonsignificant for the Mentor component. In Model 2, however, the Mentor component statistically significantly predicted by the cognitive/behavioural orientation $(\beta=0.39, \mathrm{P}<0.001)$ and negatively predicted by the psychodynamic/psychoanalytic orientation $(\beta=-0.12, \mathrm{P}<0.05)$.

Although one variable, i.e., workload, reached significance in Model 1 for the Resource Supplier component, the overall model was nonsignificant. In Model 2, this component was positively predicted by the humanistic/experiential orientation $(\beta=0.25, \mathrm{P}<0.001)$, psychodynamic/psychoanalytic orientation $(\beta=0.16, \mathrm{P}<0.01)$, and cognitive/behavioural orientation $(\beta=0.15, \mathrm{P}<0.01)$ and negatively predicted by the systemic/postmodern orientation $(\beta=-0.13, \mathrm{P}<0.05)$.

Remedy Distributor was significantly predicted by length of practice $(\beta=0.21, \mathrm{P}<0.001)$ and highest level of severity $(\beta=0.15, \mathrm{P}<0.01)$ in Model 1 . In Model 2 , both variables remained significant. Furthermore, the component was negatively predicted by the humanistic/experiential orientation $(\beta=-0.17, \mathrm{P}<0.01)$. 
Table 1. Description of metaphor variables.

Metaphor

A doctor who treats an illness

A guide who accompanies a client/patient in his or her personal development

A coach who trains a client/patient

A teacher who gives homework to a client/patient and who educates him or her

An educator who oversees a client/patient

A detective who strives to trace the source of a client/patient's problems

An adviser who offers recommendations

A consultant who offers an independent assessment to a client/patient

A confessor to whom a client/patient confides what lies heavy on him or her or what he or she is ashamed for

A repairer who fixes what is not working

A model for the client/patient

A friend or caregiver who the client/patient does not have in the real world

The metaphors appear in the same order as they did in the questionnaire.

Table 2. Summary of principal component analysis of the relationships' metaphors (pattern matrix).

\begin{tabular}{lcccc}
\hline Items & Mentor & Resource Supplier & Remedy Distributor & com. \\
\hline Coach & 0.81 & & -0.38 & 0.12 \\
\hline Teacher & 0.81 & & 0.40 & 0.71 \\
\hline Educator & 0.62 & & 0.32 & 0.60 \\
\hline Adviser & 0.55 & 0.20 & -0.11 & 0.53 \\
\hline Confessor & & 0.80 & 0.22 & 0.62 \\
\hline Friend & & 0.75 & 0.55 \\
\hline Detective & 0.32 & 0.53 & 0.33 \\
\hline Model & 0.31 & 0.50 & 0.76 & 0.41 \\
\hline Consultant & & 0.42 & 0.33 \\
\hline Guide & & 0.23 & 0.61 \\
\hline Doctor & 0.22 & 0.15 & 0.44 & 0.50 \\
\hline Repairer & 3.30 & 0.34 & 1.39 & 0.43 \\
\hline $\begin{array}{l}\text { Eigenvalue } \\
\text { of variance }\end{array}$ & 19.7 & 1.64 & \\
\hline
\end{tabular}

Component loadings over 0.40 appear in italics; loadings less than 0.10 were removed.

Table 3. Results of regression analyses.

\begin{tabular}{|c|c|c|c|c|c|c|}
\hline \multirow[t]{2}{*}{ Predictors } & \multicolumn{2}{|c|}{ Mentor } & \multicolumn{2}{|c|}{ Resource Supplier } & \multicolumn{2}{|c|}{ Remedy Distributor } \\
\hline & Model 1 & Model 2 & Model 1 & Model 2 & Model 1 & Model 2 \\
\hline Gender $^{\circ}$ & -0.05 & -0.07 & 0.00 & 0.03 & 0.04 & 0.04 \\
\hline Length of practice & -0.02 & -0.01 & 0.06 & 0.03 & $0.21 * * *$ & $0.19 * * *$ \\
\hline Highest problem severity & -0.01 & -0.04 & -0.04 & -0.05 & $0.15^{* *}$ & $0.13 *$ \\
\hline Workload & -0.10 & -0.08 & $0.13 *$ & 0.07 & -0.03 & -0.02 \\
\hline Frequency of supervision & -0.04 & -0.03 & 0.03 & -0.01 & -0.01 & -0.02 \\
\hline $\begin{array}{l}\text { Theoretical orientation } \\
\text { Cognitive/behavioral } \\
\text { Humanistic/experiential } \\
\text { Psychodynamic/psychoanalyti } \\
\text { Systemic/postmodern }\end{array}$ & & $\begin{array}{c}0.39 * * * \\
0.00 \\
-0.12 * \\
-0.09\end{array}$ & & $\begin{array}{c}0.15^{* *} \\
0.25^{* * *} \\
0.16^{* *} \\
-0.13^{*}\end{array}$ & & $\begin{array}{c}0.10 \\
-0.17 * * \\
0.09 \\
-0.02\end{array}$ \\
\hline $\begin{array}{l}R^{2} \\
\Delta R^{2} \\
n\end{array}$ & \multicolumn{2}{|r|}{$0.19^{* * *}$} & 0.03 & $\begin{array}{l}0.19 * * * \\
0.16^{* * *}\end{array}$ & $0.07 * * *$ & $\begin{array}{c}0.11 * * * \\
0.04 * *\end{array}$ \\
\hline
\end{tabular}

$N=370$. Intercepts were omitted. Values represent standardized regression coefficients. Asterisks indicate significance level: $* \mathrm{P}<0.05, * * \mathrm{P}<0.01$, and $* * * \mathrm{P}<0.001 .{ }^{\circ} \mathrm{A}$ positive value means that a component was preferred by women. 


\section{Discussion}

Using data from an online survey on Czech psychotherapists and counselors, we explored facets of psychotherapy relationships from the practitioner's perspective expressed using a set of metaphors. The descriptive analysis revealed that the single most widely endorsed metaphor for the practitioner's role in the therapeutic relationship was guide. This metaphor signifies a non-directive companion who helps clients find their way to a desired state of being, which is consistent with the Rogerian concept of the therapeutic relationship (Rogers, 1957). Today, Rogers' contribution is considered as a pan-orientation concept (Cooper, 2008) that likely resonates with most practitioners' experiences. However, the reason for the popularity of this metaphor may also be that it is most likely used by psychotherapy trainers to define the role of the therapist, and it may have been simply reproduced by the participants as a cliché, without giving it the same amount of critical consideration as they did the other metaphors. Nevertheless, except for educator, all other metaphors were perceived to capture some aspect of the psychotherapist's role as well.

Principal component analysis indicated the existence of three underlying components of the metaphors, specifically, Mentor, Resource Supplier, and Remedy Distributor. The Mentor component was defined by metaphors that suggested the practitioner teaches, trains, or supervises the client. In this sense, they share an element of directivity and explicit guidance or mentoring. However, they also seem to share an implicit non-pathologizing attitude, a focus on clients' personal growth, and the utilization of their potential. From the perspective of a teacher or a coach, a client is not somebody to be fixed or cured. Rather, it is someone in need of direction, instruction, and supervision. Furthermore, having a lack of skills is not an illness per se. Instead, it is a natural developmental stage from which a client can evolve to another, more advanced stage.

The Mentor component was more highly endorsed by practitioners with a cognitive/behavioral orientation, which agrees with the more directive nature of this orientation. Furthermore, it was negatively related to the psychodynamic/psychoanalytic orientation, which also corresponds to the relative reluctance of insight-oriented therapists to provide their clients with explicit instructions (Scaturo, 2002). Surprisingly, the Mentor component was unrelated to any of the demographic and practice-related variables, suggesting that it is a matter of a therapist's personal preference or, more likely, client-treatment matching (Beutler \& Harwood, 2000).

The Resource Supplier component was composed of a group of metaphors that suggest the therapist is available as a resource for the client. The therapist may offer many different resources, including information or counsel, new insights or perspectives, a close relationship, a safe space for the client's disclosure, empathy, support, acceptance, inspiration, or even a personal example for the client to follow. The influence is, however, non-directive in that the therapist does not impose his or her influence on the client, and the client is free to choose how to use the resources being offered. This component resembles Beisecker and Beisecker's (1993) metaphor of consumerism.

The reported use of the Resource Supplier component was positively associated with the humanistic/experiential, psychodynamic/psychoanalytic, and cognitive/behavioral orientations. The more practitioners endorsed any of these orientations, the more they tended to identify the role of a resource provider as descriptive of their therapeutic approach. This makes sense if we consider the orientations as reservoirs of the resources, whether they be psychodynamic interpretations, authentic relationships, provision of corrective experience, or the therapist modeling of assertive behavior. Surprisingly, the use of this component was negatively related to the systemic/postmodern orientation, which suggests that practitioners of this orientation are less inclined to reflect on their work this way and that, instead, they strive to adopt a more neutral attitude (Schlippe \& Schweitzer, 1998). Furthermore, practitioners who indicated higher workloads reported that they tended to find this component slightly more descriptive of their approach than those practitioners who reported fewer sessions per week, although this was partly confounded with theoretical orientation. This is an interesting finding with no straightforward interpretation. It is possible, for instance, that those who have a more intensive practice do so because they are more comfortable providing many types of resources to their clients, or because, based on their more intensive immersion in psychotherapy practice, they consider themselves more skilled at providing these resources.

The metaphors loading on the third component, Remedy Distributor, characterize a perspective from which clients are ill or disordered and therapists are experts who can cure them or repair what has gone wrong. It is implicit in this perspective that the clients do not possess the resources or the abilities needed to recover and that therapist expertise is necessary to produce change. Consistent with the medical model, the therapist is the agent of change, and the client is a recipient of the treatment. The three metaphors that loaded on this component received the lowest average scores which means that, overall, the participants found them rather unsuitable to describe the role of the therapists. This corresponds to the fact that the medical model has been largely criticized as inconsistent with psychotherapy (Elkins, 2009; Wampold, 2001). However, this was not true for all participants and the existence of this component suggests that the medical model may be relevant under some circumstances. This component can be roughly compared to Beisecker and Beisecker's (1993) metaphor of paternalism. 
It is further evident that this component was endorsed more by practitioners who worked with a more disturbed clientele, which suggests that the Remedy Distributor role is more easily evoked in this context. Furthermore, the endorsement of this component was negatively related to the humanistic/experiential orientation, which is consistent with the non-pathologizing nature of this orientation (Cain, 2002). Somewhat surprisingly, however, the endorsement was also higher with higher levels of practitioner experience. This relationship may have been confounded with the setting within which the practitioners worked: practitioners in health services and armed and rescue services reported, on average, twice as many years of practice than those in social services and educational settings. At the same time, respondents in the former two settings had clients with more severe problems than those in the latter two settings.

\section{Limitations}

Several limitations must be considered when generalizing the results of this study. First, the list of metaphors was non-exhaustive. It was composed by researchers with a humanistic/experiential orientation and even though a considerable effort was dedicated to its development, it may be biased. Future studies may employ a more extensive list of metaphors.

Second, the questionnaire captured an overall selfassessment of the suitability of the metaphors. It is possible that the meanings ascribed by participants to the metaphors differed from those assumed by the researchers. Moreover, the meanings of the metaphors may also not be easily transferable to other cultures and/or languages.

Third, the use of metaphors allows researchers to capture implicit and otherwise inaccessible meanings. A considerable amount of subjective inference and imagination was, however, required during the interpretation of the PCA results. Although the emphasis was placed on discussion and consensus, it is possible that another group of researchers would have arrived at a different interpretation of the components.

Fourth, the questionnaire was based on the participants' self-assessment of their therapeutic approach. Although Castonguay et al. (2017) demonstrated that practitioners can recall accurately the types of techniques they used, Santa Ana et al. (2008) suggested that the reliability of self-report can be limited.

Fifth, the combination of several recruitment methods does not allow us to estimate the response rate. However, trying to impose more control over the recruitment process would significantly reduce the sample size. A considerable limitation is the low degree of representation of the cognitive/behavioral orientation relative to the remaining orientations. That said, this reflects that only two of more than 40 Czech training institutes teach cognitive-behavioral therapy.

\section{Conclusions and implications}

This study has indicated that the practitioner's role in the therapeutic relationship can be explored using a metaphorical approach. The metaphor considered most accurate by the practitioners to capture the nature of the therapeutic relationship was that of guide. Furthermore, the analysis demonstrated that the plenitude of metaphors can be meaningfully reduced to three mutually independent components: a directive, mentor-like approach focused on personal growth (i.e., Mentor); a non-directive approach based on the provision of cognitive and/or emotional resources for the client (i.e., Resource Supplier); and an expert approach in which the client is perceived as a recipient of treatment (i.e., Remedy Distributor). The components were related to practitioners' self-rated theoretical orientations in a non-trivial pattern, suggesting that these components capture dimensions cutting across these orientations and, thus, define psychotherapy and counseling relationships in a more general sense. In case the model is confirmed by future research, it will provide researchers, as well as practitioners, with a useful tool to reduce the complexity of the therapeutic role into a set of three independent components that may be related to different aspects of the psychotherapy process and outcome. Future studies can explore if these three aspects of the therapeutic relationship are differentially effective with various clients' conditions (e.g., depression), characteristics (e.g., level of psychological mindedness), and expectations (e.g., supportive vs. confrontational approach).

Due to its imaginative and holistic character, the metaphorical approach can be used in psychotherapy practice and supervision. The three components, as well as the individual metaphors, can be used to reflect on the nature and quality of the therapeutic relationship with a client. Knowing what relational role a client attributes to the therapist and what he or she expects from the therapist in the therapeutic relationship is essential for the therapist to plan interventions. Metaphors can allow the therapist and the client to explore aspects of the therapeutic relationship that are inaccessible by the rational-analytic approach. However, metaphors should be used with caution. In a study on public political communication, Keefer and Landau (2015) have shown that relationship metaphors may elicit defensive information processing in people with avoidant attachment. Although we cannot automatically extrapolate this finding to the therapeutic context, therapists should exercise caution when using such metaphors in conversations with their clients.

Metaphors can be also used to reflect on the nature and form of the therapeutic relationship in the context of supervision and training. Trainees and supervisors may elicit metaphors that express their perception of a particular therapeutic case. Again, metaphors may help to verbalize the implicit and intuitive knowledge. Thus, they may sensitize trainees to various nuanced aspects of the 
psychotherapy relationship. However, readers should bear in mind that metaphors are not meant to replace rationalanalytic concepts and, thus, sacrifice the precision and unambiguity in the study of the therapeutic relationship. Albeit rich in connotative meaning, metaphors are fuzzy concepts that allow for multiple interpretations. Therefore, they are meant to serve as a complementary source of information that makes the picture more complete.

\section{References}

Angus, L. E., \& Rennie, D. L. (1988). Therapist participation in metaphor generation: Collaborative and noncollaborative styles. Psychotherapy: Theory, Research, Practice, Training, 25(4), 552-560. doi: https://doi.org/10.1037/h0085381

Angus, L. E., \& Rennie, D. L. (1989). Envisioning the representational world: The client's experience of metaphoric expression in psychotherapy. Psychotherapy: Theory, Research, Practice, Training, 26(3), 372-379. doi: https://doi.org/ 10.1037/h0085448

Austin, W., Bergum, V., Nuttgens, S., \& Peternelj-Taylor, C. (2006). A re-visioning of boundaries in professional helping relationships: Exploring other metaphors. Ethics \& Behavior, 16(2), 77-94. doi: https://doi.org/10.1207/s15327019 eb1602_1

Beisecker, A. E., \& Beisecker, T. D. (1993). Using metaphors to characterize doctor-patient relationships: Paternalism versus consumerism. Health Communication, 5(1), 41-58. doi: https://doi.org/10.1207/s15327027hc0501_3

Beutler, L. E., \& Harwood, T. M. (2000). Prescriptive psychotherapy: A practical guide to systematic treatment selection. Oxford: Oxford University Press.

Burlingame, G. M., McClendon, D. T., \& Alonso, J. (2011). Cohesion in group therapy. Psychotherapy, 48(1), 34-42. doi: https://doi.org/10.1037/a0022063

Cain, D. J. (2002). Defining characteristics, history, and evolution of humanistic psychotherapies. In D. J. Cain \& J. Seeman (Eds.), Humanistic psychotherapies: Handbook of research and practice (1st ed., pp. 3-54). Washington, DC: American Psychological Association.

Carter, A. H. (1989). Metaphors in the physician-patient relationship. Soundings: An Interdisciplinary Journal, 72(1), 153-164.

Castonguay, L. G., Janis, R. A., Youn, S. J., Xiao, H., McAleavey, A., Boswell, J. F., ... O'Leary Wiley, M. (2017). Clinicians' prediction and recall of therapeutic interventions: Practice research network study. Counselling Psychology Quarterly, 30(3), 308-322. https://doi.org/10.1080/ 09515070.2017 .1334628

Cooper, M. (2008). Essential research findings in counselling and psychotherapy: The facts are friendly. Los Angeles, CA: Sage.

Cooper, M., Norcross, J. C., Raymond-Barker, B., \& Hogan, T. P. (2019). Psychotherapy preferences of laypersons and mental health professionals: Whose therapy is it? Psychotherapy, 56(2), 205-216. doi: https://doi.org/10.1037 /pst0000226

Corsini, R. J. (2008). Introduction. In R. J. Corsini \& D. Wedding (Eds.), Current psychotherapies (pp. 1-14). Belmont: Thompson.

Crits-Christoph, P., Gibbons, M. B. C., \& Mukherjee, D. (2013). Psychotherapy process-outcome research. In M. J. Lambert
(Ed.), Bergin and Garfield's handbook of psychotherapy and behavior change (6th ed., pp. 298-340). Hoboken, NJ: John Wiley \& Sons.

Curtin, J. (2017). lmSupport: Support for Linear Models. $R$ package version 2.9.8. https://CRAN.R-project.org/package $=\operatorname{lmSupport}$

Elkins, D. N. (2009). The medical model in psychotherapy: Its limitations and failures. Journal of Humanistic Psychology, 49(1), 66-84. doi: https://doi.org/10.1177/0022167807307901

Fernández-Álvarez, H., García, F., Lo Bianco, J., \& Corbella Santomá, S. (2003). Assessment questionnaire on the personal style of the therapist PST-Q. Clinical Psychology and Psychotherapy, 10(2), 116-125. doi: https://doi.org/ 10.1002/cpp.358

Fox, J., \& Weisberg, S. (2011). An $\{R\}$ companion to applied regression (2nd ed.). Thousand Oaks, CA: Sage.

Gelso, C. J., \& Carter, J. A. (1985). The relationship in counseling and psychotherapy: Components, consequences, and theoretical antecedents. The Counseling Psychologist, 13(2), $155-243$

Gelso, J. C., \& Hayes, J. A. (2007). Countertransference and the therapist's inner experience: Perils and possibilities. London: Routledge.

Grencavage, L. M., \& Norcross, J. C. (1990). Where are the commonalities among the therapeutic common factors? Professional Psychology: Research and Practice, 21(5), 372378. doi: https://doi.org/10.1037//0735-7028.21.5.372

Henson, R. K., \& Roberts, J. K. (2006). Use of exploratory factor analysis in published research: Common errors and some comment on improved practice. Educational and Psychological Measurement, 66(3), 393-416. doi: https://doi. org/10.1177/0013164405282485

Horn, J. L. (1965). A rationale and test for the number of factors in factor analysis. Psychometrica, 30(2), 179-185. doi: https://doi.org/10.1007/BF02289447

Horvath, A. O., Del Re, A. C., Flückiger, C., \& Symonds, D. (2011). Alliance in individual psychotherapy. Psychotherapy, 48(1), 9-16. doi: https://doi.org/10.1037/a0022186

Huang, F. (2015). hornpa: Horn's (1965) test to determine the number of components/factors. $R$ package version 1.0. https://CRAN.R-project.org/package=hornpa

Keefer, L. A., \& Landau, M. J. (2015). Frighteningly similar: Relationship metaphors elicit defensive information processing. Social Psychological and Personality Science, 6(8), 931-939. doi: https://doi.org/10.1177/1948550615597975

Kopp, R. R. (1995). Metaphor therapy: Using client generated metaphors in psychotherapy. Bristol, PA: Brunner/Mazel.

Kuhn, T. S. (1996). The structure of scientific revolutions (3rd ed.). Chicago, IL: University of Chicago Press. doi: https://doi.org/10.7208/chicago/9780226458106.001.0001

Lakoff, G., \& Johnson, M. (2003). Metaphors we live (2nd ed.). Chicago, IL: The University of Chicago Press.

Leary, D. E. (Ed.). (1990). Metaphors in the history of psychology. Cambridge, UK: Cambridge University Press.

LimeSurvey Project Team. (2015). LimeSurvey: An open source survey tool. LimeSurvey Project Hamburg, Germany. Available from: http://www.limesurvey.org

Norcross, J. C. (2011). Psychotherapy relationships that work: Evidence-based responsiveness (2nd ed.). New York, NY: Oxford University Press.

O'Connor, B. (2000). SPSS and SAS programs for determining the number of components using parallel analysis and Velicer's MAP test. Behavior Research Methods, Instru- 
ments, \& Computers, 32(3), 396-402. doi: https://doi.org/ 10.3758/BF03200807

Orlinsky, D. E., \& Rønnestad, M. H. (2005). How psychotherapists develop: A study of therapeutic work and professional growth. Washington, DC: American Psychological Association.

R Core Team. (2017). R: A language and environment for statistical computing. R Foundation for Statistical Computing, Vienna, Austria. Available from: https://www.R-project.org/.

Revelle, W. (2016). psych: Procedures for Personality and Psychological Research. Evanston, IL: Northwestern University. Available from: http://CRAN.R-project.org/package= psych Version=1.6.4.

Řiháček, T., \& Roubal, J. (2017a). Personal therapeutic approach: concept and implications. Journal of Psychotherapy Integration, 27(4), 548-560.

Řiháček, T., \& Roubal, J. (2017b). The proportion of integrationists among Czech psychotherapists and counselors: A comparison of multiple criteria. Journal of Psychotherapy Integration, 27(1), 13-22. https://doi.org/10.1037/int0000069

Řiháček, T., \& Roubal, J. (2019). Využívání psychoterapeutických technik v praxi [The use of psychotherapy techniques in practice]. E-psychologie, 13(1), 1-17. https://doi.org/10.29364/ epsy. 335

Řiháček, T., \& Roubal, J. (2020). Common principles of psychotherapeutic change: Patterns of use. British Journal of Guidance and Counselling, 48(4), 489-499. https://doi.org/ $10.1080 / 03069885.2018 .1503230$

Rogers, C. R. (1957). The necessary and sufficient conditions of therapeutic personality change. Journal of Consulting
Psychology, 21(6), 95-103. doi: https://doi.org/10.1037/ h0045357

Rowat, R., Stefano, J. De, \& Drapeau, M. (2008). The role of patient-generated metaphors on in-session therapeutic processes. Archives of Psychiatry \& Psychotherapy, 10(1), 21-27. doi: https://doi.org/10.1007/BF00120585

Safran, J. D., Muran, J. C., \& Eubanks-Carter, C. (2011). Repairing alliance ruptures. Psychotherapy: Theory, Research, Practice, Training, 48(1), 80-87. doi: https://doi.org/10.1037 /a0022140

Santa Ana, E. J., Martino, S., Ball, S. A., Nich, C., Frankforter, T. L., \& Carroll, K. M. (2008). What is usual about "treatment-as-usual"? Data from two multisite effectiveness trials. Journal of Substance Abuse Treatment, 35(4), 369-379. http://doi.org/10.1016/j.jsat.2008.01.003

Scaturo, D. J. (2002). Technical skill and the therapeutic relationship: A fundamental dilemma in cognitive-behavioral and insight-oriented therapy. Family Therapy, 29(1), 1-21.

Schlippe, A. von, \& Schweitzer, J. (1998). Lehrbuch der systemischen Therapie und Beratung. Göttingen: Vandenhoeck \& Ruprecht.

Wampold, B. E. (2001). The great psychotherapy debate: Models, methods, and findings. Mahwah, NJ: Lawrence Erlbaum Associates.

Young, J. S., \& Borders, L. D. (1999). The intentional use of metaphor in counseling supervision. The Clinical Supervisor, 18(1), 137-149. doi: https://doi.org/10.1300/J001v18n01_09

Ziv-Beiman, S. (2013). Therapist self-disclosure as an integrative intervention. Journal of Psychotherapy Integration, 23(1), 59-74. doi: https://doi.org/10.1037/a0031783 